\title{
THE IMPACT OF STIGMA ON THE PREVENTION OF HIVIAIDS
}

\author{
K. Okechukwu \\ Department of Obstetrics and Gynaecology. University of Benin Teaching Hospital, \\ Benin City, Edo State
}

\section{INTRODUCTION}

HIVIAIDS had remained the topical disease condition that has afflicted man in recent times. The search for a definite cure still continues even as varying statistical data continue to expose the devastation caused by the disease worldwide. A significant proportion of the worlds' population is burdened by the disease. Worldwide estimate of people affected is still in the neighbourhood of 40 million despite greater awareness of the disease. Though the incidence of the disease has fallen significantly in the Northern and Western hemispheres, what with greater awareness and effective and widespread use of antiretroviral drugs (ARV'S), the incidence in most third world countries has remained unacceptably high. Presently, Africa is said to carry over $80 \%$ of the disease burden. The spread of the disease has been influenced by varied factors including behavioural, cultural, political, moral and religious factors. These influences underlie the development of stigmas. Erving Goffman (1963) is credited for conceptualizing and creating a framework for the study of stigma. In his landmark book "Notes on the Management of Spoiled Identity" the described stigma as "an attribute that is deeply discrediting within a particular social interaction"11 - in this instance, HIV/AIDS.

\section{Stigma Defined}

HIVIAIDS - related stigma refers to unfavourable attitudes, beliefs, and polices directed towards people perceived to have HIVIAIDS as well as towards their significant others and loved ones, close associates, social groups and communities. It includes prejudice, discounting, discrediting and discrimination directed at people perceived to have HIV or AIDS, and the individuals, groups and communities with which they are associated. These patterns of prejudices play into and strengthen existing social inequalities - especially those of gender, sexuality and race - that are at the root of HIV- related stigma and stigma expression.

Stigma expression can be in 3 ways, namely; (a) Instrumental Expression, (b) Symbolic Expression, (c) and Courtesy Expression ${ }^{2}$. While Instrumental Stigma expression involves an individual's concern about the risk of his contacting AIDS including the individuals' perception of the disease, Symbolic Stigma expression is through political, religions, social or other values. Courtesy expression of stigma involves the stigmatization of people connected to the issues of HIVIAIDS or HIV Positive people for example non governmental organizations. All 3 types of stigma expression have various manifestations.

\section{Manifestations of Stigma}

These may involve the following:

(a) Ostracism, rejection and avoidance of people living with AIDS (PLWHA) (b) discrimination against PLWHA (c) compulsory HIV testing without prior consent or protection of confidentiality (d) violence against persons who are perceived to have AIDS or to be infected with HIV (e) Quarantine of persons with HIV. The prejudices, expressions and manifestations of stigma have been reflected by several surveys.

(b) Surveys conducted recently in the USA show that a lot of people still believe that HIV can be transmitted casually. $40 \%$ of people believe sharing a drinking glass could put then at risk $-20-30 \%$ of those surveyed stated that they would be uncomfortable with sending their children to schools with children living

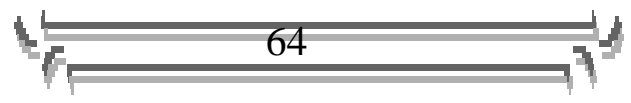


with AIDS. $20 \%$ of the people believe those who were sexually exposed to AIDS through sex and drugs got what they deserve. One survey published by the America behavioural scientists $(1999 \text {, vol } 42.7)^{2}$ indicate that (a) most Americans still associate AIDS with homosexuality and bisexuality (b) persons contracting HIV sexually are blamed for their infection-especially so for homosexual and bisexual men. (c) Sizable majority of people equate all malemale sexual behaviour with AIDS (d) misconception about HIV transmission is correlated with sexual prejudices. Many other studies from different countries have shown similar associations of stigma as a product and reflection of broader social problems, for example illness and ignorance. Stigma enables people to believe they are not at risk of HIV thereby impacting HIV prevention.

\section{Effects of Stigma on HIV Prevention}

Prevention of HIV is hampered by stigma in many ways. Due to stigma some people and governments have chosen to withhold information about preventing the transmission of HIV and have supported laws and policies that make the victims of stigma more vulnerable to HIV infection. The stigma associated with carrying drugs around may prevent the HIV infected individual from commencing treatment ${ }^{7}$. Knowledge of the HIV status of an individual may result in outright layout from job or layout and sack from job for other reasons ${ }^{5}$. Most importantly stigma may limit or prevent the stigmatized individual access to care ${ }^{8}$.

Access to care is affected by stigma in one of 3 ways, namely (a) Barrier to care of HIV positive individuals, (b) reluctance of health care providers to treat individual with HIV (c) Stigmatization of provider of ancillary or support services to PLWHA. Barrier to care is reflected by the result of Kaiser Health Roll report $(2000)^{6}$ which suggests that the fear of being stigmatized has some relationship to peoples decision about getting tested for HIV. Half of the people surveyed felt very or somewhat concerned that people would think less of them if they discovered that they have been tested. $8 \%$ of the people who have never tested for HIV said that the worries about confidentially play a part in their decision not to have the test. The findings also found that majority of people at risk of contacting HIV are more likely to seek testing if offered confidentially.

Confidentiality is required of health professionals who treat HIV positive individuals. Also there's the need for sensitivity to the individuals concerns about stigma. Both is often lacking in most health professionals $^{6}$. What is often present however is the fear of contagion and the fear of death. There is also a general fear of stigmatization of themselves because of their work with HIV positive patients (Courtesy stigma or Secondary stigma).

Stigma experienced by providers of ancillary and support services is shown by a study that indicated that volunteers who never anticipated their stigmatization being less satisfied and burned out than those who expected the stigma ${ }^{3}$. Many of these volunteers from the study perceive HIV stigmatization to be more than cancer stigmatization. Potential stigmatization may prevent non-volunteers from donating to AIDS organization.

\section{STIGMA PREVENTION STRATEGIES}

Seeing therefore that stigma has far reaching effect on the control of HIVIAIDS, it is necessary to put in place stigma limitation and prevention strategies. Anti-stigma legislation will go a long way to address this issue. Strategies to prevent stigma include the location of HIV prevention programs within targeted communities. These programs should target their messages at both HIV positive and HIV negative people. Prevention message should counteract the phenomenon where individuals disassociate their own sexual behaviours with the risk of contacting HIV. Also these messages must promote non-stigmatizing mages of PLWHA. These messages need to be ongoing and continuous. There is the need for increased media and cultural exposure

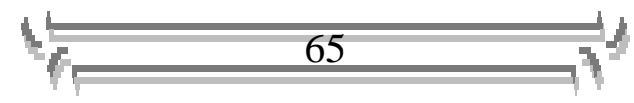


of PLWHA as it has been proven that personal experiences of PLWHA can have profound impact on individual and community perception of the disease. Though recent Sentinel Surveys in Nigeria has shown a continuous decline from $5.8 \%$ in 2001 to 5.0 in 2003 and $4.4 \%$ in 2005, the role of the media in preventing strategies that led to these improvements cannot be under estimated. Unfortunately however, the active role of National Action Committee on AIDS (NACA) in its public enlightenment through television and radio jingles including cell phone messages has been stopped due to socio-political pressures. These messages were reaching everyone irrespective of location in Nigeria as the English versions had their corresponding local translations ${ }^{9}$. These unstable policies reflect the complex nature of the Nigerian society. If this is allowed to continue, the gains already made may be reversed. Finally the need for better coordination between Community-based Organizations, Funders and HIV Prevention Providers can never be overemphasized. Emphasis should however be placed on the tackling of homophobia (the hatred and fear of homosexuals). Though the practice of homosexuality cannot be said to be as prevalent in our culture and environment as in the western world, the extent of the practice has not been documented by any survey. In fact, the impact of stigmatization in management of HIVIAIDS in our environment awaits full evaluation by studies in Nigeria.

\section{REFERENCES}

1. Goffman E Stigma: Notes on the management of spoiled identity New Jersey: Prentice Hall, 1963.
2. Burris S. Studying the legal management of HIV related Stigma Am Behav Scientist 1999: 42(7) 1229-43.

3. Snyder M, Omoto. A. M, Crain, A.N. Stigmatization for AIDS volunteers. Furnished for their good deeds. American Behavioural scientist 1999:42 (7) 1175-92.

4. Herek GM, Capitanio JP, Widaman KF. HIV - related stigma and Knowledge in the United States: Prevalence and trends, 1991 - 1999. Am J Public Health 2002; 92 (3) 1371-7.

5. Herek GM, Gillis JR, Cogan J. Psychological sequelae of hate crime victimization among Lesbian, gay, and bisexual adults. J. Consult Clin Psychol. 1999; 67(6) 945-51.

6. Kaiser Health Poll Report. Relationship between stigma and HIV testing 2000. Available at http://www.kff.org/ healthpoll.report.

7. Stall $\mathrm{R}$, et al. Decisions to get HIV tested and to accept antiretroviral therapies among gay/bisexual men implications for secondary prevention efforts. J acquired immune deficiency syndromes Hum retrovirology. 1996; 11:151-60.

8. Annas G. Protecting Px from discrimination: the Americans with disabilities Act and HIV infection. N Engl J Med. 1998; 339:1255-9 